\title{
Study on the Promotion Strategy of College Students’ Reading and Writing Ability Under the Micro Network Environment
}

\author{
LIU Xiao-zheng, LIU Jin-feng \\ Changchun University, Changchun, China
}

\begin{abstract}
Network media has become more and more involved in our daily life. It has become a part of modern life that cannot be stopped or rejected. Then, how to correctly face the changes in the Internet era is placed in front of everyone. Students need to "learn how to use the media to get their all-round development, effectively prevent the foreign information pollution, and actively guide students to a truly rational attitude for WeChat, blog and micro-blog”. It is a kind of media literacy being confronted with the network's ability to consciously resist the harmful information, but also to benefit their own development and firmly grasp the information, so as to make full use of the convenience of network self promotion. "Screen reading" network plays an important role in college students' life, and the fragmentation, the text features of the writing ability of college students also have a strong impact; this paper focuses on the influence of college students in the network reading and writing patterns on their writing ability and influence. From the perspective of media literacy education for college students, writing ability and reading ability provide a feasible way.
\end{abstract}

Keywords: reading ability, writing ability, college students, micro network environment

\section{Preface}

In recent years, China's online education has experienced one leap after another, and information technology has become a new milestone in the development of modern education, which has become an important symbol of the modernization of education. A variety of innovative modern educational technologies continue to promote the traditional teaching methods, content, models, and systems, ideas, and many other changes. "Education" is no longer satisfied with a blackboard and a chalk traditional classroom teaching model, and more new knowledge has begun to teach students through modern educational technology. Therefore, in the traditional teaching mode, it calls for reform, and the teachers are scarce and the teaching hours are saturated, which means the open network teaching emerges as the times require. For years, writing courses have been searching for breakthroughs in teaching content, teaching methods, and teaching methods. Many college teachers have the experience of trying to do so. If writing teaching can keep pace with the times, seize the opportunities of

\footnotetext{
This paper is an important part of the project-13th Five-Year Social Science Research Project "Study on the Promotion Strategy of College Students' Reading and Writing Ability Under the Network Environment”, Jilin Province Department of Education.

LIU Xiao-zheng, Master, associate professor, English Department, Changchun University, Changchun, China.

LIU Jin-feng, Master, associate professor, English Department, Changchun University, Changchun, China.
} 
modern teaching techniques and methods, and actively try network teaching, then it can be regarded as a breakthrough in the reform of writing teaching. Therefore, in the course of the teaching reform research, the author takes the students' active participation in blog, micro-blog and WeChat as the platform, and makes some preliminary research on the cultivation and improvement of college students' writing ability under the network environment. With micro-blog and WeChat as the representatives of micro dissemination in the convenience and enjoyment of the same time, its fragmentation, super wood communication model also gives us a systemic impact of thinking. "Micro" is not only a way of life imagination, but also a kind of cultural behavior pattern that directly transfers and moves our life emotion quickly. College students use web information to understand events beyond their own experience. As a result, micro media influence their senses and psychology, making their cultural forms change dramatically with the technological changes of media.

\section{Analysis of Network Environment in Micro Era}

\section{WeChat}

WeChat is a product that Tencent Inc. in 2011 launched a quick send text, pictures, and it supports multiplayer voice chat and mobile phone chat software. Users can send messages quickly via mobile phones or web platforms. WeChat provides the public platform, circle of friends, and the message push function, which means users can "shake" and "search number", "near" and so on to sweep the two-dimensional code to add friends and pay attention to the public platform. At the same time, it will be content to share with friends and see the exciting content to share the circle of friends. As of November 2013, WeChat registered users exceeded to 600 million which is currently Asia's largest instant messaging software. The new era of college students failed to do with the computer "looks together", but the mobile phone is really a moment which cannot be separated, so WeChat writing is also the top priority of the topic research. WeChat writing no length limit, because pictures, voice, and video collocation can be called natural micro-blog that is more convenient, and accumulated a lot of people, so that students naturally joined them, little more occasional homework pressure. What's more, a large amount of information push also provides the guarantee for students' extracurricular reading.

\section{Micro-blog}

Micro-blog is a platform based on user relations, information sharing, dissemination and access. In the network environment, users can form personal communities through clients such as WEB, WAP, and so on, update the information with 140 words, and realize instant sharing. Generally speaking, micro-blog provides such a platform where people can be either as an audience, in micro-blog browsing one's interest in information. And it also can be published as a publisher, micro-blog content for others to browse. Micro-blog released content is generally shorter which can hence be its name. Micro-blog's biggest feature is the rapid release of information and the rapid dissemination of information. If one has 2 million listeners (fans), his message will be sent to 2 million people instantly. In the course of students' construction of blog, micro-blog construction is a flash in the pan. However, even in the rapid development of WeChat's momentum and there are still many students at the same time on micro-blog and WeChat releasing information, it can be seen that the use of micro-blog will still have a long way to go. 


\section{Blog}

The term "blog" comes from the English word "Blog" (not translated). As a noun, "Blog" refers to the web log, and it is a kind of communication with personal thoughts, knowledge collection link publishing. While as a verb, it refers to the process of publishing articles in various forms in the virtual space in the blog. In network times, blog is the second E-mail, BBS, QQ after the fourth network exchange way which is the personal Internet age, "reader's digest", and it not only represents a new way of life and work, and it represents a new way of learning. A few years ago, teachers began to encourage students to build blogs, and some classroom writing exercises even required students to finish on blogs. Now, with the careful construction of their students, their blogs have become spectacular, and some blogs are still very impressive. In addition, teachers also organize blog design and creative contests on campus regularly to attract more students to participate in blog construction.

\section{Strategies for Improving College Students’ Writing Ability}

\section{Promotion Goal}

Writing objectives can closely describe their views around the subject which needs to use appropriate examples to demonstrate arguments, and enrich the content, structure, and language fluency. Learn to use the Internet to obtain information, analyze information, process information, and apply the useful information that students have collected to writing. The training requirements to blog, micro-blog, WeChat for the writing platform, with his own way of expression, the use of text, pictures, voice, video, and other multimedia links, vivid and clear opinion combined with acoustic shadow to express their views. Therefore, the teachers of English reading and writing should have a deep understanding of the important role and advantages of micro-blog and WeChat in the ideological and political education of college students, and carry out the work in a targeted way. First of all, teachers should guide and supervise students' information-seeking on the micro-blog or WeChat. For example, when some news or information is released on the WeChat, the students tend to take it as the fact and even quote it in their writing indiscriminately, therefore, ideological and political education to students is of great significance and the cultivation of students' critical thinking is necessary so that the students can make the distinction between facts and opinions themselves and find out the problem in the first time. Secondly, college students like to share their emotions and experience in their life on the WeChat or micro-blog, which also calls for teachers' intense attention so that the teachers can make use of the materials or topics that are close to students' real life in class. In this way, the students are not "spectators” but "participators” who will take active part in the discussion on the hot topics. On teachers' part, they should respond in a timely manner, through their proposed content, filter the information for the students in order to carry out ideological and political education properly. Thirdly, to make students feel the English reading and writing at all times, and the teacher's sincere concern for and care for the students which can make it easier for students to open their hearts to English reading and writing teachers.

From the perspective of "micro era", intelligent mobile phone, notebook computer, tablet computer and mobile terminal using more and more groups of students in the mobile terminal will become one of the important carriers of ideological and political education of college students. Since 2009, the China issued 3G licenses, mobile phone media which has become the mainstay of the people to obtain information and foreign exchange in all sectors of society; it has increasingly high degree of attention, and some experts said the mobile phone media 
as the "fifth media". Compared to other traditional media, the "fifth media" has more advantages, such as the subject of infinite space, and two aspects of universality, economy and effectiveness of the object, the communication network communication become personalized, targeted and two-way of internationalization. With the rapid development of mobile intelligent terminal, the ideological and political education through innovative thinking means a new strategy to actively explore a variety of mobile carrier that is the carrier of ideological and political education of college students who need to form the micro era problem. Some surveys show that $43 \%$ of students spend more than three hours a day on mobile phones, and $50 \%$ of students spend at least one to three hours. It is visible that "micro era" arrives, so that the use of mobile phones has become a normal student daily life. The mobile terminal intelligent fast and widely used; not only the students are more easy to accept reading and writing English teachers are easy to master, and the mobile terminal has gradually become a new ideological and political education in the position. The mobile terminal is called a carrier of education, which in its release contains the world of education, life education, moral education, ideological and political education of the information dissemination process, and reading and writing English teachers need to aim for the standard screening of education information in the release of educational information.

College English reading and writing teachers of referred education have the obvious requirement of network cultural environment; they need to rely on a good cultural environment with using modern management means to broaden the channels of reading and writing education. The use of wireless clients to build and promote public opinion is also a good choice to strengthen the use of mobile terminals based media platform. For example, the school can be a department as a unit to establish independent client, let the students to download the client, publicity for legal education, moral education, psychological counseling, life service information, timely guidance on students' legal and moral, psychological and other aspects, so that students can better meet the micro information era of diversification, the impact to establish a correct outlook on life. In addition, teachers should also strengthen the supervision of the campus network, supervise the use of students in the network, and find that the abnormal situation cannot be shelved. Teachers should often find students to talk, and become students in learning, life, and other aspects of the right-hand man. In this environment, the human environment of the network will form.

\section{Teaching Process}

Micro-blog and the Wechat are essentially application platforms; they are mainly for the special writing terminal with diversity, that is to say no matter when and where, the user can freely update micro-blog, WeChat, and so on, and micro-blog, which makes WeChat become a free information interaction platform to show the real people "self", college students are true in the micro platforms, and their feelings in this platform has been released. "Micro-blog is a kind of non identity media, and it is an important way to improve the spiritual communication between teachers and students”. Micro-blog and WeChat can build a harmonious teacher-student interaction and communication platform, and it does not directly face to face communication, while to minimize the probability of occurrence of psychological estrangement between teachers and students. In the daily life, for an English reading and writing teachers, many students are holding the psychological fear, and the students in learning and life difficulties, which means grievances are reluctant to read and write English teachers, say they prefer to talk to classmates and friends who are willing to actively seek the help of teachers of English reading and writing the 
true friendship between teachers and students, and it is not easy to achieve. Micro-blog and WeChat will be able to meet the students' the highest degree of emotional expression, and students can express their ideas in the micro communication platform, although the main status has been highlighted, but also provides a good platform and opportunity for the status of teachers and students between teachers and students to communicate, to avoid face-to-face communication embarrassment in favor to establish a harmonious and equal relationship between teachers and students.

In the writing process, the teacher will teach the students to write independently after they have made the teaching objectives and writing requirements which is clear to the students. The students in the process of writing their own search materials can be uploaded to the network space, also through the link function that will show excellent material and all the other students who can also enjoy collective communication, discussion through the circle of friends. In the process of writing, teachers can also provide students with their own model essays to further stimulate students' interest in writing. After a certain period of time, when the students have finished their homework, the teachers and students are free to choose to read other people's works to make comments or to praise. English reading and writing teachers can also browse the amount and the number of points as the scoring reference standard. Under the guidance of constructivism, with modern teaching theory and situational education theory, the teaching model is combined with the network writing environment providing a reference model for teachers and students to learn from the network writing. It gives full play to the unique function of blog, micro-blog, WeChat in the development of writing skills and reading skills, which can mobilize the enthusiasm of the students by the way of sharing autonomy to promote the communication between teachers and students, and it is also a powerful tool to make blog, micro-blog, WeChat, and other network platform culture ingenious that become teachers' teaching and students' writing ability.

This study involves the subject from the beginning more than two years, through questionnaires, seminars, and other forms of individual talk investigation; we found that blog, micro-blog, and WeChat for college students are not new things, but can really be used much easier. Although we have tried to encourage students to use the blog, micro-blog, WeChat to record their memories of life and learning, but the statistics show that only $70 \%$ of the students can often use them, and there is a small part of students having to cope with things like these. This shows that there are still a lot of work to do in the future, using blogs, micro-blog, WeChat, and other web technologies to improve students' writing ability. In addition, the new writing model needs to construct a matching evaluation criterion. In order to adapt to the new characteristics of students' micro media creation, English reading and writing teacher should actively promote the formation of "micro" writing evaluation criteria for college students. Micro creative development evaluation criteria are based on the evaluation object and the past writing situation, which means they should pay attention to the current writing ability, and give more focus on future development. Its role is to help students diagnose writing problems to analyze the advantages and disadvantages of existing, and to provide supplier feedback information and put forward specific and targeted suggestions for improvement. Micro media writing allows students to write more creative and innovative space, so that writing can really goes into each student's life.

\section{Concrete Ways}

How can teachers and students use blog, micro-blog, and WeChat to improve the writing ability of college 
students? After more than two years of witnessing the growth of students, the study proposes the following ways can be used as a reference:

(1) Urging students to constantly update their blog, micro-blog, WeChat to update content, not only for the construction of the advantages, but also the necessary conditions and prerequisites for success. Regular updates are not only because readers like new content, but also because they can increase the intensity of student management. If students do not do regular updates, they will not take full advantage of the network potential, and blog, micro-blog, WeChat will become "barren" that cannot play a role in promoting. To this end, the author of the project team members is consciously crowded Internet access, urging students to regularly update their blog, micro-blog, and WeChat. The methods employed include writing articles actively, attracting students, and encouraging students to post and praise or comment. Micro-blog and WeChat are new media, the interaction than in the past greatly increased through the network between people, whether it is life or work arrangement, message learning arrangements, and modern people's way of life has been accustomed to using micro media to disseminate information and exchange experience feelings. Now more and more people love reading in WeChat and create a public number that can be a group or can also be personal, and the contents of the public number is also increasingly diversified involving all aspects of entertainment, life events, and so on. Recently published in WeChat, Lu Dandan thinks that positive discipline means how to correctly and effectively encourage children; this form of public welfare micro class prefers people can easily listen to lectures on WeChat. In this form, the scope of the ideological and political education has broken the traditional education scope before the change rapidly in the information age and the new media changes, the traditional ideological and political education have been powerless. In college, English reading and writing teachers must keep pace with the times, take the initiative to build and make use of the micro platform, and create a two-way interaction based on absorbing micro cultural ideas and methods on the common drive mode, ideological and political education to achieve seamless online and offline and organic integration.

(2) Suggested that students responded positively to the comments and many other bloggers (students) communication by multi message and comment, and they should participate in discussion with the establishment of a successful business interest alliance that is the key for students to blog, micro-blog, and WeChat. For students, their interests are allied to their friends and those who share similar interests. Positive message, comment, and praise can make these writers and their readers to discover new content to find a new link; a party can get more involved in cognitive, on the other hand, but also with other friends and readers to create more links to more actively participate in. It is teachers' practice to actively participate in various "new” responses to let the student feel our attention, so as to guide students to find the comment core to see the real problem, in the message delivered in the open field of vision; it can improve the depth of thinking to enhance understanding of the problem with exercise skills. College students are the successors of the socialist cause and the future society pioneer; student cadres play an important role in leading college students; student cadres play an important role in the implementation of the grass-roots management in education at the same time. Student leaders in the university campus are the progressive elements among students. They are the bridge to communicate the feelings of teachers and students and to transmit information from the school. The quality of student leaders directly affects the construction of schools and classes. In the rapid development of the information age, the using of new media does a good job in training student cadres, with the help of "micro media" to make students cadres in student groups in the mentoring role. 
With high-speed development of the network information age, how to use micro-blog, WeChat, QQ, and other micro media to do a good job in training student cadres so that the cadres of college students can achieve self management which is reading and writing English teachers to carry out ideological and political education, is an important task to complete. Under the new situation, student's cadres of the vision are more and more open and more and more active thinking, then reading and writing in English teachers can be through the micro media daily attention to the student cadres of the ideological and political activities, which often held close to the theory of student cadres of real life learning, such as reading and writing in English teachers that can establish WeChat group, QQ group by forwarding party knowledge and ideological and political education and other aspects of the video and pictures to attract the student cadres consciously that they are interested to learn. English reading and writing teachers can be also through the micro media to organize student cadres of student work, meetings, and other activities, learning together of different majors and college student cadres working methods, research method by learning from each other. Under the new era, micro media is a feedback channel between English reading and writing teachers, and student cadres and ordinary students to establish a convenient and efficient communication platform, so that students can change some prejudices and opinions on English reading and writing teacher and student cadres, and students will be given to ordinary cadres of their feedback and response to the pressure of public opinion, who always asked himself to student cadre identity. English reading and writing teachers also can use the micro platform to stimulate the student cadre's service consciousness and innovation consciousness to improve the students' participation of cadres daily management and students' ideological and political education to improve their work enthusiasm to achieve the benign complementary which is good to the effect of positive interaction.

(3) To encourage students to open access and build multi links exchange with friends to expand their circles of friends and friends to exchange links, not only can get more direct traffic, but also can expand the students' circle of friends to let friends of friends know about them. Students gain a great deal of insight into this snowball—swapping link, sometimes in excess of the accumulation of content. The students increase knowledge in the blog, micro-blog, and WeChat making new friends is an effective way to increase social experience, and this road can not only broaden their horizons, but also can increase the EQ of students for their writing ability, which means the benefit is self-evident.

(4) Students are encouraged to complete their assignments on the Internet and increase their chances of accessing the network. In recent years, many teachers in our country often use the network layout and correcting homework. With the teacher's comments and peer review, the students' writing ability and appreciation ability have been greatly improved. Teachers and students should gradually study the writing trend of micro media, and explore the characteristics of micro media writing. Teachers also need to face up to micro media writing, and guide students to seize the opportunities for micro media creation, training students to develop micro media creative learning. The timeliness of micro media creation makes it possible for students to insist on writing regularly so as to accumulate the material of life and gradually develop and improve their knowledge. In addition, through the micro media platform for college students to build interest exchange group, the formation of "writing and reading - exchange" circle of friends in the peer mutual assessment of the atmosphere is to let students independently raise micro media creation ability in this environment, and the formation of benign space, mutual learning to appreciate each other. 


\section{Conclusion}

The 21st century is called the Internet age, and the traditional model of teaching characters will inevitably encounter changes, at this time, how to improve and how to deal with this situation become every teacher's problem and they are engaged in writing teaching which needs to seriously consider the question. Without the students' listening and practice, without the students' work, the writing class will always be a class without cheers. These two years of exploration and practice of proof try to let the students write in the blog, micro-blog, and WeChat, and a party can urge students to contact with the network. Understand the network, using the Internet, but also keep pace with the times, using the Internet to explore the effective way of writing teaching. Therefore, teachers have reason to believe that it is indeed a good and effective way to develop students' writing ability through blogging, micro-blog, and WeChat writing. It not only cultivate the students' confidence in writing, but also greatly stimulate their interest in writing to improve the writing level of the students with reducing typos, and the text expression is smooth with the idea to use words, expression techniques that are also more and more skilled and wonderful. Two years of efforts prove that our teaching reform is successful, and it is believed that the future writing class will be full of flowers and applause with colorful text paved the stage of life.

\section{References}

Cai, J. G. (2011). A comparative study of online peer feedback for Chinese college students' English writing. Foreign Language Circles, 2, 65-72.

Chen, X. R. (2013). The study of English newspaper reading teaching to improve students writing ability. Chinese Journal of Medical Education, 10, 1023-1026.

Fan, B., Wang, F., \& Huang, J. X. (2015). The study on using the mobile Internet to innovate college students' ideological guidance under the "micro age"-Taking Minzu University of China as an example. Ethnic Education Research, 6, 31-34.

Luo, C. L. (2016). A brief discussion on the cultivation of college students' healthy network psychology from the perspective of "micro era”. School Party Building and Ideological Education, 20, 47-49.

Long, X. Z., \& Chen, F. F. (2017). Thanksgiving education for college students in the micro age: Challenges, opportunities and countermeasures. Hunan Social Sciences, 2, 188-193.

Miu, Y., \& Gao, P. (2014). The influence and countermeasures of the media “micro era” on the behavior patterns of college Students [J]. School Party Building and Ideological Education, 10, 54-55.

Sun, M. L. (2012). Research on network resources and college English writing teaching. Educational Research, 1, $130-133$.

Wang, X. F. (2016). A study of the effect of formative assessment on college students' English writing. Journal of PLA Foreign Languages Institute, 39(4), 102-110.

Yang, H. J. (2012). Students’ English writing teaching under the network environment. Chinese Education Journal, s1, 73-74. 